\title{
Desempenho produtivo do agrião d'água cultivado em solo sob telas de sombreamento
}

\author{
Andréia Cristina Silva Hirata( ${ }^{(1)}$ e Edson Kiyoharu Hirata ${ }^{(2)}$
}

\begin{abstract}
(1)Agência Paulista de Tecnologia dos Agronegócios, Polo Regional Alta Sorocabana, Caixa Postal 298, CEP $19015-970$ Presidente Prudente, SP, Brasil. E-mail: andreiacs@apta.sp.gov.br (2)Universidade do Oeste Paulista, Faculdade de Agronomia, Rodovia Raposo Tavares, Km 572, Limoeiro, CEP 19067-175 Presidente Prudente, SP, Brasil. E-mail: hirataedson@hotmail.com
\end{abstract}

\begin{abstract}
Resumo - O objetivo deste trabalho foi avaliar o desempenho produtivo do agrião d'água (Rorippa nasturtium-aquaticum) cultivado em solo sob diferentes telas de sombreamento e a pleno sol, em dois ciclos consecutivos (muda e rebrota). Os tratamentos consistiram do cultivo do agrião d'água sob telas de sombreamento preta $35 \%$, prata $35 \%$, vermelha $35 \%$, branca/prata $20 \%$ e a pleno sol (controle), em delineamento de blocos ao acaso com quatro repetições. No primeiro ciclo de desenvolvimento do agrião d'água, houve incremento de até $59 \%$ na produção de massa fresca sob sombreamento. A massa fresca proveniente da rebrota do agrião d'água variou de $419 \mathrm{~g} \mathrm{~m}^{-2}$, a pleno sol, a $3.027,7 \mathrm{~g} \mathrm{~m}^{-2}$ sob a tela prata $35 \%$. Houve incremento do tamanho das folhas e da altura do dossel sob sombreamento. A temperatura do solo na profundidade de $4,0 \mathrm{~cm}$ foi reduzida em até $3^{\circ} \mathrm{C}$ pelas telas de sombreamento, em comparação ao tratamento a pleno sol. Telas de sombreamento promovem aumento na produtividade, no tamanho das folhas e na altura do dossel do agrião d'água cultivado em solo, nos ciclos de muda e rebrota, com maior produtividade sob as telas preta $35 \%$ e prata $35 \%$.
\end{abstract}

Termos para indexação: Nasturtium officinale, Rorippa nasturtium-aquaticum, ciclos de cultivo, cultivo em solo, sombreamento artificial.

\section{Agronomic performance of watercress grown in soil under shade cloth}

\begin{abstract}
The objective of this work was to evaluate the agronomic performance of watercress (Rorippa nasturtium-aquaticum) grown in soil under different shade clothes and full sun in two development cycles (seedling and regrowth). The treatments consisted of watercress grown under $35 \%$ black, $35 \%$ silver, $35 \%$ red, $20 \%$ white/silver shade clothes, and under full sun (control), in a randomized complete block design with four replicates. In the first watercress development cycle, there was an increase in fresh weight of up to $59 \%$ under shade. The fresh matter from watercress regrowth ranged from $419 \mathrm{~g} \mathrm{~m}^{-2}$, under full sun, to $3,027.7 \mathrm{~g} \mathrm{~m}^{-2}$ under the $35 \%$ silver shade cloth. Leaf size and canopy height increased under shade. Soil temperature at the $4.0-\mathrm{cm}$ depth was reduced up to $3^{\circ} \mathrm{C}$ with the shade clothes, when compared to the full sun treatment. Shade clothes promote greater yield, leaf size, and canopy height in watercress grown in soil, during the seedling and regrowth cycles, with higher yield for the $35 \%$ black and $35 \%$ silver shade screens.
\end{abstract}

Index terms: Nasturtium officinale, Rorippa nasturtium-aquaticum, crop cycles, growing in soil, artificial shading.

\section{Introdução}

O agrião d'água [Rorippa nasturtium-aquaticum (L.) Hayek] é uma brassicácea semiperene, adaptada a clima ameno e cultivada no outono-inverno, na maioria das regiões. A cultivar tradicional Folha Larga produz plantas vigorosas, de alta capacidade de perfilhamento, com folhas tenras e arredondadas. O caule é rastejante, do qual se desenvolvem finas raízes aquáticas, que retiram nutrientes do meio líquido, e raízes pivotantes, que fixam a planta ao solo. Por se tratar de uma planta semiaquática, a espécie se desenvolve adequadamente em água corrente (Filgueira, 2000).

A luz e a temperatura estão entre os fatores que mais limitam o cultivo de espécies vegetais em diferentes épocas e locais. As hortaliças, quando cultivadas em condições de temperatura acima da adequada para o seu crescimento, apresentam redução do ciclo de cultivo, com reflexos na sua produtividade e na sua qualidade (Puiatti \& Finger, 2005). Plantas de agrião cultivadas em câmaras de crescimento, a $25^{\circ} \mathrm{C}$, submetidas a baixo fluxo de fótons fotossintéticos $\left(265 \mu \mathrm{mol} \mathrm{m}{ }^{-2} \mathrm{~s}^{-1}\right)$ 
e a 12 horas de fotoperíodo, produziram $62 \%$ de incremento de massa seca em comparação às plantas expostas a elevado fluxo $\left(435 \mu \mathrm{mol} \mathrm{m}^{-2} \mathrm{~s}^{-1}\right)$ e a 8 horas de fotoperíodo (Palaniswamy et al., 1997).

Isso indica que as condições climáticas de algumas regiões podem limitar a produção de espécies hortícolas durante parte do ano. A busca por um melhor ambiente para o cultivo de hortaliças tem sido o foco principal de inúmeras pesquisas. Atualmente, são muitas as opções disponíveis no mercado com relação aos tipos de estruturas e de materiais que podem ser usados para modificar o ambiente e adequá-lo às necessidades das culturas (Feltrim et al., 2006). Nesses casos, o uso de técnicas de proteção de cultivos é uma alternativa para viabilizar a produção (Otto et al., 2000).

De acordo com Queiroga et al. (2001), em regiões tropicais, as telas de sombreamento contribuem para reduzir a intensidade de radiação solar que incide diretamente sobre as plantas, o que traz benefícios para a fotossíntese, com consequente aumento no seu desempenho produtivo. Going et al. (2008) relatam que o agrião d'água apresenta boa aclimatação fisiológica à ambiente com baixa intensidade luminosa.

Telas de sombreamento tem sido avaliadas na produção de flores (Nomura et al., 2009), plantas medicinais e aromáticas (Brant et al., 2009; Lima et al., 2011; Corrêa et al., 2012), e hortaliças (Queiroga et al., 2001; Otoni et al., 2012; Queiroz et al., 2014). Os resultados obtidos são indicativos de que fatores como latitude local, época do ano e horário do dia determinam a atenuação da radiação solar pela tela plástica. Isso é importante, uma vez que a recomendação da densidade ideal de tela para o cultivo de determinada espécie pode variar de uma região para outra (Pezzopane et al., 2004).

Os efeitos do manejo do ambiente são variáveis, e as respostas das plantas diferem até mesmo entre cultivares da mesma espécie (Stamps, 2009). As espécies podem apresentar mecanismos de adaptação diferentes quanto ao acúmulo e ao uso dos pigmentos fotossintéticos, no que se refere à captação de luz em ambientes de menor luminosidade e à proteção contra danos fotoquímicos em ambientes de maior luminosidade (Gonçalves et al., 2001).

O objetivo deste trabalho foi avaliar o desempenho produtivo do agrião d'água (Rorippa nasturtium-aquaticum) cultivado em solo sob diferentes telas de sombreamento e a pleno sol, em dois ciclos consecutivos (muda e rebrota).

\section{Material e Métodos}

O experimento foi realizado no setor de olericultura do Polo Regional Alta Sorocabana, da Agência Paulista de Tecnologia dos Agronegócios, em Presidente Prudente, SP $\left(22^{\circ} 07^{\prime} 21^{\prime \prime S}, 51^{\circ} 23^{\prime} 17^{\prime \prime} \mathrm{W}\right.$, a $460 \mathrm{~m}$ de altitude), no período de setembro a dezembro de 2014, com dois ciclos (muda e rebrota) de desenvolvimento da cultura.

De acordo com a classificação de Köppen, o clima é do tipo Aw, tropical chuvoso com inverno seco, com temperatura média do mês mais frio superior a $18^{\circ} \mathrm{C}$ e precipitação do mês mais seco inferior a $60 \mathrm{~mm}$ (Centro Integrado de Informações Agrometeorológicas, 2014). Os dados de precipitação pluvial e de temperaturas máxima, média e mínima, no período avaliado, estão descritos na Figura 1.

O experimento foi realizado em Argissolo Vermelho-Amarelo. A análise química do solo, de acordo com o método proposto por Raij et al. (2001), apresentou as seguintes características na camada arável, de 0-20 cm: $\mathrm{pH}$ em $\mathrm{CaCl}_{2}$ de 6,4; $15 \mathrm{~g} \mathrm{dm}^{-3}$ de matéria orgânica; $\mathrm{V}$ de $90 \% ; 73 \mathrm{mmol}_{\mathrm{c}} \mathrm{dm}^{-3} \mathrm{de} \mathrm{Ca}$; $13 \mathrm{mmol}_{\mathrm{c}} \mathrm{dm}^{-3}$ de $\mathrm{Mg} ; 10 \mathrm{mmol}_{\mathrm{c}} \mathrm{dm}^{-3} \mathrm{de} \mathrm{H}+\mathrm{Al} ; 85 \mathrm{mg}$ $\mathrm{dm}^{-3}$ de $\mathrm{P}_{\text {resina }}$; e $2,3,8,7,13,7,6,0,7$ e $0,05 \mathrm{mg} \mathrm{dm}^{-3}$

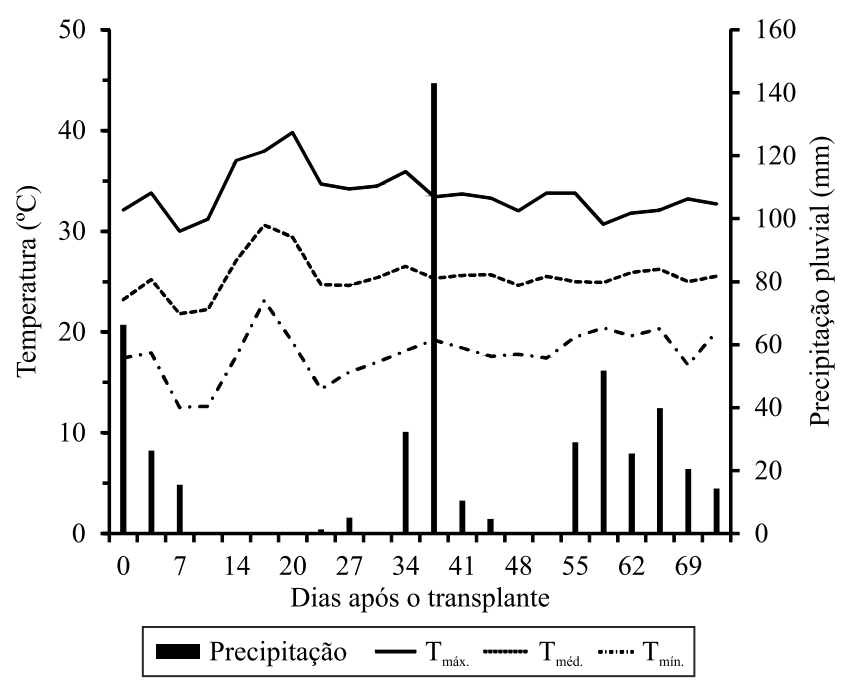

Figura 1. Dados meteorológicos de precipitação pluvial e de temperaturas máxima, média e mínima durante o cultivo do agrião d'água (Rorippa nasturtium-aquaticum), de 26/9 a 9/12/2014. Fonte: Centro Integrado de Informações Agrometeorológicas (2014). 
de $\mathrm{K}, \mathrm{Zn}, \mathrm{Fe}, \mathrm{Mn}, \mathrm{Cu}$ e B, respectivamente. A classe textural do solo é arenosa, com 812, 111 e $77 \mathrm{~g} \mathrm{~kg}^{-1} \mathrm{de}$ areia total, silte e argila.

Utilizou-se o delineamento experimental de blocos ao acaso, com quatro repetições. Os tratamentos consistiram do cultivo do agrião d'água sob telas com $35 \%$ de sombreamento na cor preta, $35 \%$ na cor prata, $35 \%$ na cor vermelha, $20 \%$ na cor branca/prata e a pleno sol (controle). As telas foram colocadas individualmente nas parcelas experimentais e casualizadas, com quatro repetições de cada tela. Foram confeccionados canteiros com $0,15 \mathrm{~m}$ de altura, e as telas foram colocadas a $1,0 \mathrm{~m}$ da superfície dos canteiros e fechadas nas laterais.

A semeadura do agrião d'água foi realizada em bandejas de plástico de 288 células, que continham substrato comercial para hortaliças, em casa de vegetação. As mudas (dez plantas por alvéolo) foram transplantadas para o campo quando apresentavam $5,0 \mathrm{~cm}$ de altura, em 26/9/2014. A unidade experimental foi constituída por quatro linhas de agrião de $2,1 \mathrm{~m}$ de comprimento, com espaçamento de $0,25 \mathrm{~m}$ entre linhas e $0,30 \mathrm{~m}$ entre plantas, o que totalizou 28 plantas por parcela.

As adubações de plantio e cobertura no campo foram baseadas nas recomendações de Trani et al. (2014). Após a rebrota, a adubação foi realizada via água de irrigação. A irrigação foi veiculada pelo sistema de gotejamento, tendo-se utilizado três fitas gotejadoras ao longo das parcelas.

O comprimento e a largura das folhas foram determinados ao final dos dois ciclos da cultura. Aos 34 dias após o transplante, foi avaliada a temperatura do solo na profundidade de $4,0 \mathrm{~cm}$, às $8 \mathrm{~h} 30$, às $11 \mathrm{~h}$, às $13 \mathrm{~h} 30 \mathrm{e}$ às $16 \mathrm{~h}$.

O primeiro ciclo de desenvolvimento foi avaliado 38 dias após o transplante das mudas, quando a primeira colheita do agrião d'água foi realizada. Para a coleta das amostras, dois quadros de $0,30 \mathrm{~m}$ de lado foram colocados na porção central da parcela, e as plantas contidas nos quadros foram cortadas a $2,0 \mathrm{~cm}$ do solo. Após a coleta, o restante das plantas também foi cortado para avaliação do segundo ciclo de desenvolvimento da cultura (rebrota).

As plantas coletadas foram pesadas e separadas em folhas e talo para avaliação da massa de matéria fresca e seca das partes das plantas. Para isso, as plantas foram secas em estufa de circulação forçada de ar, a $65^{\circ} \mathrm{C}$, até atingir peso da massa de matéria seca constante.
O segundo ciclo de desenvolvimento da cultura foi avaliado aos 36 dias do corte, com os mesmos procedimentos do primeiro ciclo. Por ocasião da colheita, realizou-se a leitura indireta da clorofila, por meio do medidor SPAD-502 (Konica Minolta Sensing Inc., Sakai, Osaka, Japão), em amostras de dez folhas completamente expandidas do topo do dossel, com três medidas por folha.

Os dados foram submetidos à análise de variância, e as médias foram comparadas pelo teste de Tukey, a 5\% de probabilidade.

\section{Resultados e Discussão}

Foram observadas temperaturas elevadas durante os dois ciclos de desenvolvimento do agrião d'água, com temperaturas máximas de 30 a $39^{\circ} \mathrm{C}$ (Figura 1), uma condição de elevado estresse para a espécie, adaptada a temperaturas amenas.

No início da manhã, às $8 \mathrm{~h} 30$, não houve diferença na temperatura do solo entre os tratamentos, o que é explicado pelos menores efeitos da radiação solar nesse período. A partir das $11 \mathrm{~h}$, o tratamento a pleno sol apresentou aumento de $1,8^{\circ} \mathrm{C}$ na temperatura do solo, na profundidade de $4,0 \mathrm{~cm}$, em comparação às telas preta $35 \%$ e prata $35 \%$. As telas vermelha $35 \%$ e branca/prata $20 \%$ apresentaram valores intermediários de temperatura do solo (Tabela 1). Sales et al. (2014) verificaram que a tela vermelha, como subcobertura de uma estufa coberta com filme plástico, não reduziu a temperatura máxima média do ambiente, enquanto a tela prata reduziu, em $4,0^{\circ} \mathrm{C}$, a temperatura do interior da estufa.

Com o aumento da temperatura das $13 \mathrm{~h} 30$ às $16 \mathrm{~h}$, a temperatura do solo não diferiu entre os tratamentos

Tabela 1. Temperatura do solo, em diferentes horários, na profundidade de $4,0 \mathrm{~cm}$, em cultivo de agrião d'água (Rorippa nasturtium-aquaticum) produzido em solo sob diferentes telas de sombreamento e a pleno sol ${ }^{(1)}$.

\begin{tabular}{lcccc}
\hline Tratamento & \multicolumn{4}{c}{ Temperatura $\left({ }^{\circ} \mathrm{C}\right)$} \\
\cline { 2 - 5 } & $8 \mathrm{~h} 30$ & $11 \mathrm{~h}$ & $13 \mathrm{~h} 30$ & $16 \mathrm{~h}$ \\
\hline Vermelha 35\% & $21,7 \mathrm{Da}$ & $23,6 \mathrm{Cab}$ & $25,2 \mathrm{Bb}$ & $26,6 \mathrm{Ab}$ \\
Preta 35\% & $21,7 \mathrm{Ba}$ & $22,9 \mathrm{Bb}$ & $24,6 \mathrm{Ab}$ & $25,8 \mathrm{Ab}$ \\
Branca/prata $20 \%$ & $21,5 \mathrm{Da}$ & $23,9 \mathrm{Cab}$ & $25,4 \mathrm{Bb}$ & $26,7 \mathrm{Ab}$ \\
Prata 35\% & $21,7 \mathrm{Ba}$ & $22,9 \mathrm{Bb}$ & $24,3 \mathrm{Ab}$ & $25,5 \mathrm{Ab}$ \\
Pleno sol (controle) & $21,0 \mathrm{Ca}$ & $24,7 \mathrm{Ba}$ & $27,7 \mathrm{Aa}$ & $28,5 \mathrm{Aa}$ \\
\hline
\end{tabular}

${ }^{(1)}$ Médias seguidas de letras iguais, maiúsculas nas linhas e minúsculas nas colunas, não diferem pelo teste de Tukey, a 5\% de probabilidade. 
com as telas, mas, a pleno sol, foi superior em até $3^{\circ} \mathrm{C}$. Pezzopane et al. (2004) também constataram atenuação da temperatura do solo com o uso de telas de sombreamento. Segundo esses autores, a modificação microclimática provocada pelas telas, provavelmente, também reduz a perda de água por evapotranspiração. Dessa forma, as telas minimizaram o efeito da radiação solar direta no ambiente de cultivo.

Com base na produtividade e nos componentes de produção do primeiro ciclo de desenvolvimento do agrião d'água (Tabela 2), o sombreamento promoveu impacto positivo no peso da massa de matéria fresca da parte aérea, especialmente do talo, com incremento de até $59 \%$ de produtividade em relação ao tratamento controle (cultivo a pleno sol). Além de reduzir a radiação, a queda da temperatura no solo sob as telas também pode ter contribuído para a melhor adaptação da cultura sob as telas. Bezerra Neto et al. (2005) observaram que os efeitos negativos de temperatura e luminosidade elevadas na produtividade de hortaliças podem ser minimizados de forma significativa com telas de sombreamento. Conforme Pezzopane et al. (2004), o balanço de radiação determina a energia disponível para fotossíntese e para processos como evaporação, aquecimento ou resfriamento do ar e do solo. Assim, a redução do saldo de radiação promovido pelas telas deve resultar em modificações microclimáticas significativas, que alteram o crescimento e o desenvolvimento das plantas sob a tela plástica.
Não houve diferença entre os tratamentos quanto à massa de matéria seca total, o que evidencia que o efeito das telas na massa de matéria fresca foi resultante do maior teor de água, principalmente nos talos, nas plantas cultivadas sob as telas. A maioria das hortaliças folhosas apresenta elevado teor de água, como verificado na parte aérea do agrião $(91,2 \%)$ em cultivo protegido, no sistema de hidroponia (Ohse et al., 2012). No presente trabalho, o teor de água na parte aérea do agrião d'água foi de $91,9 \%$ (a pleno sol) a $93,9 \%$ (sob tela prata $35 \%$ ). Desse modo, o cultivo sob as telas resultou em talos mais tenros, o que é um importante atributo de qualidade apreciado pelo consumidor.

No final do segundo ciclo de cultivo, houve maior diferença entre os tratamentos (Tabela 2), em que os ambientes com as telas preta e prata, com 35\% de sombreamento, apresentaram desempenho produtivo superior. $\mathrm{O}$ tratamento a pleno sol promoveu menor capacidade de rebrota, o que é atribuído ao baixo desempenho produtivo do primeiro ciclo de cultivo, que, associado às altas temperaturas, resultou em impacto negativo no acúmulo das massas fresca e seca. De acordo com Going et al. (2008), plantas de agrião d'água provenientes de fragmentos vegetativos com maior massa inicial apresentam maior incremento na massa final. Isso confirma os resultados obtidos no presente trabalho, em que os tratamentos com elevada produção de massa de matéria fresca apresentaram

Tabela 2. Produção de plantas, após a primeira colheita, provenientes de mudas e de rebrota do agrião d'água (Rorippa nasturtium-aquaticum) produzido em solo sob diferentes telas de sombreamento e a pleno sol $^{(1)}$.

\begin{tabular}{|c|c|c|c|c|c|c|}
\hline \multirow[t]{2}{*}{ Tratamento } & \multicolumn{3}{|c|}{ Massa de matéria fresca $\left(\mathrm{g} \mathrm{m}^{-2}\right)$} & \multicolumn{3}{|c|}{ Massa de matéria seca $\left(\mathrm{g} \mathrm{m}^{-2}\right)$} \\
\hline & Parte aérea & Folha & Talo & Parte aérea & Folha & Talo \\
\hline & \multicolumn{6}{|c|}{ Mudas } \\
\hline Vermelha $35 \%$ & $2.293,5 \mathrm{ab}$ & $726,6 a$ & $1.566,8 \mathrm{a}$ & $145,5 \mathrm{a}$ & $63,2 \mathrm{a}$ & $82,3 a$ \\
\hline Preta $35 \%$ & $2.558,4 \mathrm{a}$ & $892,8 \mathrm{a}$ & $1.665,6 \mathrm{a}$ & $162,9 \mathrm{a}$ & $75,3 \mathrm{a}$ & $87,7 \mathrm{a}$ \\
\hline Branca/prata $20 \%$ & $2.452,8 \mathrm{a}$ & $813,9 \mathrm{a}$ & $1.638,9 \mathrm{a}$ & $164,4 \mathrm{a}$ & $71,3 \mathrm{a}$ & $93,1 \mathrm{a}$ \\
\hline Prata $35 \%$ & $2.691,1 \mathrm{a}$ & $950,3 \mathrm{a}$ & $1.740,8 \mathrm{a}$ & $162,8 \mathrm{a}$ & $72,6 a$ & $90,2 \mathrm{a}$ \\
\hline \multirow[t]{2}{*}{ Pleno sol (controle) } & $1.695,8 \mathrm{~b}$ & $650,0 \mathrm{a}$ & $1.045,8 \mathrm{~b}$ & $136,9 \mathrm{a}$ & $59,0 \mathrm{a}$ & $77,9 \mathrm{a}$ \\
\hline & \multicolumn{6}{|c|}{ Rebrota } \\
\hline Vermelha $35 \%$ & $1.965,9 \mathrm{bc}$ & $649,6 a$ & $1.316,3 b$ & $139,7 \mathrm{ab}$ & $61,5 \mathrm{a}$ & $78,2 \mathrm{~b}$ \\
\hline Preta $35 \%$ & $2.868,2 \mathrm{ab}$ & $830,1 \mathrm{a}$ & $2.038,1 \mathrm{a}$ & $160,6 \mathrm{ab}$ & $62,1 \mathrm{a}$ & $98,5 \mathrm{ab}$ \\
\hline Branca/prata $20 \%$ & $1.669,9 \mathrm{c}$ & $557,0 \mathrm{a}$ & $1.112,9 \mathrm{~b}$ & $126,7 \mathrm{~b}$ & $53,4 \mathrm{a}$ & $73,2 b$ \\
\hline Prata $35 \%$ & $3.027,7 \mathrm{a}$ & $814,9 \mathrm{a}$ & $2.212,8 \mathrm{a}$ & $177,5 \mathrm{a}$ & $61,9 \mathrm{a}$ & $115,6 \mathrm{a}$ \\
\hline Pleno sol (controle) & $419,0 \mathrm{~d}$ & $177,1 \mathrm{~b}$ & $241,9 \mathrm{c}$ & $62,3 c$ & $25,2 \mathrm{~b}$ & $37,1 \mathrm{c}$ \\
\hline
\end{tabular}

${ }^{(1)}$ Médias seguidas de letras iguais, nas colunas, não diferem pelo teste de Tukey, a 5\% de probabilidade. 
maior produção de rebrota após o corte, no primeiro ciclo de cultivo.

O peso da massa de matéria fresca do tratamento a pleno sol representou cerca de $14 \%$ do peso obtido pelas plantas cultivadas sob a tela prata $35 \%$, o que mostra efeito positivo do uso de ambiente protegido no desenvolvimento da cultura. Incrementos na produtividade com o cultivo sob telas de sombreamento, em comparação ao tratamento a pleno sol, também foram descritos para outras espécies (Brant et al., 2009; Espindola Junior et al., 2009; Otoni et al., 2012; Silva et al., 2015).

Ao contrário do observado para as plantas provenientes de mudas, a massa seca das plantas oriundas da rebrota apresentou diferença significativa entre os tratamentos (Tabela 2). A massa seca total das folhas e do talo foi inferior no tratamento a pleno sol. Esse resultado pode ser explicado pela maior massa de matéria fresca produzida nos tratamentos com telas, no primeiro ciclo de desenvolvimento, o que acarretou maior capacidade de rebrota no segundo ciclo e aumentou a diferença entre os tratamentos, com impacto na produção de massa de matéria seca.

Quanto à morfologia da planta, constatou-se que as folhas apresentaram maior comprimento e largura no cultivo sob as telas de sombreamento (Tabela 3), tanto para a muda quanto para a rebrota. Going et al. (2008) verificaram que o agrião d'água apresenta elevada plasticidade morfológica e aclimatação a condições de baixa luminosidade, em razão do aumento de área foliar, o que é importante para o uso de telas de sombreamento. Cabe destacar, no entanto, que nem todas as espécies apresentam resposta positiva ao sombreamento: em algumas plantas, há redução da produtividade com o sombreamento proporcionado pelas telas (Chagas et al., 2010; Costa et al., 2014). No segundo ciclo de desenvolvimento, também foi observada a mesma tendência no tamanho das folhas. Isso porque plantas cultivadas sob telas de sombreamento apresentam aumento da área foliar para maior interceptação da luz (Espindola Junior et al., 2009; Oliveira et al., 2011; Otoni et al., 2012; Sales et al., 2014), enquanto plantas expostas ao sol apresentam menores áreas foliares, como defesa à transpiração e à elevação da temperatura (Niinemets \& Fleck, 2002). Além disso, Ribeiro et al. (2012) apontam que a qualidade e a intensidade da radiação que incide sobre as folhas das plantas também promovem modificações na espessura do mesófilo, dos tecidos vasculares, da epiderme, da cutícula, da densidade e das demais características estomáticas, para tolerância a essas condições.

Em relação à altura do dossel, no primeiro ciclo de desenvolvimento, as plantas cultivadas sob as telas atingiram altura de até $25,6 \mathrm{~cm}$ e, a pleno sol, $13,7 \mathrm{~cm}$, ou seja, altura $55 \%$ inferior (Tabela 3 ). O incremento na altura de plantas cultivadas sob telas de sombreamento também foi relatado em outros trabalhos (Oliveira et al., 2011; Otoni et al., 2012; Lunz et al., 2014) e atribuído à redução da luminosidade, o que resulta em estiolamento da planta.

No segundo ciclo de cultivo, a altura do dossel apresentou valores baixos em todos os tratamentos. Isso pode ser explicado pelo fato de as plantas serem provenientes da rebrota e, consequentemente, apresentarem hábito mais rasteiro, decorrente do crescimento rastejante do caule.

Em relação ao índice SPAD, não houve diferença entre os tratamentos nos dois ciclos de desenvolvimento do agrião d'água. A média dos tratamentos no primeiro e no segundo ciclo de cultivo foi de 44,9 e 42,2, respectivamente. Going et al. (2008) não observaram diferenças na concentração de clorofila do agrião d'água

Tabela 3. Largura e comprimento das folhas, bem como altura do dossel de plantas de agrião d'água (Rorippa nasturtiumaquaticum) produzido em solo sob diferentes telas de sombreamento e a pleno sol ${ }^{(1)}$.

\begin{tabular}{|c|c|c|c|c|c|c|}
\hline \multirow[t]{2}{*}{ Tratamento } & \multicolumn{2}{|c|}{ Largura da folha $(\mathrm{cm})$} & \multicolumn{2}{|c|}{ Comprimento da folha $(\mathrm{cm})$} & \multicolumn{2}{|c|}{ Altura do dossel $(\mathrm{cm})$} \\
\hline & Colheita $^{(2)}$ & Rebrota $^{(3)}$ & Colheita & Rebrota & Colheita & Rebrota \\
\hline Vermelha $35 \%$ & $3,4 \mathrm{ab}$ & $3,0 \mathrm{a}$ & $3,7 \mathrm{a}$ & $3,3 \mathrm{a}$ & $25,6 \mathrm{a}$ & $10,5 \mathrm{ab}$ \\
\hline Preta $35 \%$ & $3,6 a$ & $3,1 \mathrm{a}$ & $4,0 \mathrm{a}$ & $3,2 \mathrm{a}$ & $22,8 \mathrm{a}$ & $14,7 \mathrm{a}$ \\
\hline Branca/Prata 20\% & $3,4 \mathrm{ab}$ & $2,9 a$ & $3,8 \mathrm{a}$ & $3,1 \mathrm{a}$ & $21,9 a$ & $8,9 \mathrm{ab}$ \\
\hline Prata 35\% & $3,2 \mathrm{ab}$ & $3,0 \mathrm{a}$ & $3,8 \mathrm{a}$ & $3,3 \mathrm{a}$ & $25,5 \mathrm{a}$ & $15,0 \mathrm{a}$ \\
\hline Pleno sol (controle) & $2,9 b$ & $2,0 \mathrm{~b}$ & $3,1 \mathrm{~b}$ & $2,3 \mathrm{~b}$ & $13,7 \mathrm{~b}$ & $4,2 b$ \\
\hline
\end{tabular}

${ }^{(1)}$ Médias seguidas de letras iguais, nas colunas, não diferem pelo teste de Tukey, a $5 \%$ de probabilidade. ${ }^{(2)}$ Colheita da produção de plantas provenientes de mudas. ${ }^{(3)}$ Colheita da rebrota após o primeiro corte. 
produzido sob diferentes níveis de luminosidade. Segundo os autores, a aclimatação fisiológica a baixos níveis de luz parece ser de importância secundária para a espécie.

\section{Conclusões}

1. Telas de sombreamento promovem aumento na produtividade, no tamanho das folhas e na altura do dossel do agrião d'água (Rorippa nasturtium-aquaticum) cultivado em solo, nos ciclos de muda e rebrota.

2. As telas de sombreamento preta $35 \%$ e prata $35 \%$ promovem maior produtividade do agrião d'água, em comparação às telas vermelha $35 \%$ e branca/prata $20 \%$.

\section{Referências}

BEZERRA NETO, F.; ROCHA, R.C.C.; NEGREIROS, M.Z. de; ROCHA, R.H.C.; QUEIROGA, R.C.F. de. Produtividade de alface em função de condições de sombreamento e temperatura e luminosidade elevadas. Horticultura Brasileira, v.23, p.189-192, 2005. DOI: 10.1590/S0102-05362005000200005.

BRANT, R. da S.; PINTO, J.E.B.P.; ROSA, L.F.;ALBUQUERQUE, C.J.B.; FERRI, P.H.; CORRÊA, R.M. Crescimento, teor e composição do óleo essencial de melissa cultivada sob malhas fotoconversoras. Ciência Rural, v.39, p.1401-1407, 2009. DOI: 10.1590/S0103-84782009005000083.

CENTRO INTEGRADO DE INFORMAÇÕES AGROMETEOROLÓGICAS. Monitoramento climatológico: Presidente Prudente. Disponível em: <http://www.ciiagro.sp.gov. $\mathrm{br} /$ ciiagroonline/Listagens/MonClim/LMClimLocal.asp $>$. Acesso em: 15 dez. 2014.

CHAGAS, J.H.; RIBEIRO, A.S.; PINTO, J.E.B.P.; BERTOLUCCI, S.K.V.; SANTOS, F.M.; BOTREL, P.P. Acúmulo de biomassa seca em plantas de Mentha arvensis cultivada sob diferentes malhas e níveis de sombreamento. Horticultura Brasileira, v.28, p.S3457-S3463, 2010.

CORRÊA, R.M.; PINTO, J.E.B.; REIS, É.S.; MOREIRA, C.M. Crescimento de plantas, teor e qualidade de óleo essencial de folhas de orégano sob malhas coloridas. Global Science and Technology, v.5, p.11-22, 2012.

COSTA, A.G.; CHAGAS, J.H.; BERTOLUCCI, S.K.V.; PINTO, J.E.B.P. Níveis de sombreamento e tipos de malha no crescimento e produção de óleo essencial de hortelã-pimenta. Horticultura Brasileira, v.32, p.194-199, 2014. DOI: 10.1590/ S0102-05362014000200013.

ESPINDOLA JUNIOR, A.; BOEGER, M.R.T.; MACCARI JÚNIOR, A.; REISSMANN, C.B.; RICKLI, F.L. Variação na estrutura foliar de Mikania glomerata Spreng. (Asteraceae) sob diferentes condições de luminosidade. Brazilian Journal of Botany, v.32, p.749-758, 2009. DOI: 10.1590/S0100-84042009000400013.
FELTRIM, A.L.; CECÍLIO FILHO, A.B.; REZENDE, B.L.A.; BARBOSA, J.C. Produção de chicória em função do período de cobertura com tecido de polipropileno. Horticultura Brasileira, v.24, p.249-254, 2006. DOI: 10.1590/S0102-05362006000200027.

FILGUEIRA, F.A.R. Novo manual de olericultura: agrotecnologia moderna na produção e comercialização de hortaliças. Viçosa: Ed. da UFV, 2000. 402p.

GOING, B.; SIMPSON, J.; EVEN, T. The influence of light on the growth of watercress (Nasturtium officinale $\mathrm{R}$. Br.). Hydrobiologia, v.607, p.75-85, 2008. DOI: 10.1007/s10750-008-9368-2.

GONÇALVES, J.F. de C.; MARENCO, R.A.; VIEIRA, G. Concentration of photosynthetic pigments and chlorophyll fluorescence of mahogany and tonka bean under two light environments. Revista Brasileira de Fisiologia Vegetal, v.13, p.149-157, 2001. DOI: 10.1590/S0103-31312001000200004.

LIMA, M.C.; AMARANTE, L. do; MARIOT, M.P.; SERPA, R. Crescimento e produção de pigmentos fotossintéticos em Achillea millefolium L. cultivada sob diferentes níveis de sombreamento e doses de nitrogênio. Ciência Rural, v.41, p.45-50, 2011. DOI: 10.1590/S0103-84782011000100008

LUNZ, A.M.P.; SILVA JÚNIOR, E.C.; DE OLIVEIRA, L.C. Efeito de diferentes níveis de sombreamento no crescimento inicial de Unha de gato (Uncaria tomentosa Willd.). Revista Brasileira de Plantas Medicinais, v.16, p.866-873, 2014. DOI: 10.1590/1983-084X/11 216.

NIINEMETS, U.; FLECK, S. Petiole mechanics, leaf inclination, morphology, and investment in support in relation to light availability in the canopy of Liriodendron tulipifera. Oecologia, v.132, p.21-33, 2002. DOI: 10.1007/s00442-002-0902-z.

NOMURA, E.S.; LIMA, J.D.; RODRIGUES, D.S.; GARCIA, V.A.; FUZITANI, E.J.; SILVA, S.H.M. Crescimento e produção de antúrio cultivado sob diferentes malhas de sombreamento. Ciência Rural, v.39, p.1394-1400, 2009. DOI: 10.1590/ S0103-84782009000500014.

OHSE, S.; CARVALHO, S.M.; REZENDE, B.L.A.; OLIVEIRA, J.B. de; MANFRON, P.A.; DOURADO NETO, D. Produção e composição química de hortaliças folhosas em hidroponia. Bioscience Journal, v.28, p.155-163, 2012.

OLIVEIRA, F.L. de; ARAÚJO, A.P.; GUERRA, J.G.M. Crescimento e acumulação de nutrientes em plantas de taro sob níveis de sombreamento artificial. Horticultura Brasileira, v.29, p.292-298, 2011. DOI: 10.1590/S0102-05362011000300006.

OTONI, B. da S.; MOTA, W.F. da; BELFORT, G.R.; SILVA, A.R.S.; VIEIRA, J.C.B.; ROCHA, L. de S. Produção de híbridos de tomateiro cultivados sob diferentes porcentagens de sombreamento. Revista Ceres, v.59, p.816-825, 2012. DOI: 10.1590/S0034-737X2012000600012.

OTTO, R.F.; GIMENEZ, C.; CASTILLA, N. Modificações microclimáticas sob proteção de polipropileno cultivado com espécies hortícolas em Córdoba, Espanha. Horticultura Brasileira, v.18, p.204-211, 2000. DOI: 10.1590/S0102-05362000000300013.

PALANISWAMY, U.; MCAVOY, R.; BIBLE, B. Supplemental light before harvest increases phenethyl isothiocyanate in watercress under 8-hour photoperiod. HortScience, v.32, p.222-223, 1997. 
PEZZOPANE, J.E.M.; OLIVEIRA, P.C. de; REIS, E.F. dos; LIMA, J.S. de S. Alterações microclimáticas causadas pelo uso de tela plástica. Engenharia Agrícola, v.24, p.9-15, 2004. DOI: 10.1590/S0100-69162004000100002.

PUIATTI, M.; FINGER, F.L. Fatores climáticos. In: FONTES, P.C.R. (Ed.). Olericultura: teoria e prática. Viçosa: Ed. da UFV, 2005. p.17-30.

QUEIROGA, R.C.F.; BEZERRA NETO, F.; NEGREIROS, M.Z.; OLIVEIRA, A.P.; AZEVEDO, C.M.S.B. Produção de alface em função de cultivares e tipos de telas de sombreamento nas condições de Mossoró. Horticultura Brasileira, v.19, p.192-196, 2001. DOI: 10.1590/S0102-05362001000300006.

QUEIROZ, J.P. da S.; COSTA, A.J.M. da; NEVES, L.G.; SEABRA JUNIOR, S.; BARELLI, M.A.A. Estabilidade fenotípica de alfaces em diferentes épocas e ambientes de cultivo. Revista Ciência Agronômica, v.45, p.276-283, 2014. DOI: 10.1590/ S1806-66902014000200007.

RAIJ, B. van; ANDRADE, J.C. de; CANTARELLA, H.; QUAGGIO, J.A. (Ed.). Análise química para avaliação da fertilidade de solos tropicais. Campinas: IAC, 2001. p.173-199.
RIBEIRO, M. de N.O.; CARVALHO, S.P. de; PEREIRA, F.J.; CASTRO, E.M. de. Anatomia foliar de mandioca em função do potencial para tolerância a diferentes condições ambientais. Revista Ciência Agronômica, v.43, p.354-361, 2012. DOI: 10.1590/S1806-66902012000200019.

SALES, F.A. de L.; BARBOSA FILHO, J.A.D.; BARBOSA, J.P.R.A.D.; VIANA, T.V. deA.; FREITAS, C.A.S. de. Telas agrícolas como subcobertura no cultivo de alface hidropônica. Ciência Rural, v.44, p.1755-1760, 2014. DOI: 10.1590/0103-8478cr20120633.

SILVA, E.M.N.C. de P. da; FERREIRA, R.L.F.; RIBEIRO, A.M.A. de S.; ARAÚJO NETO, S.E. de; KUSDRA, J.F. Desempenho agronômico de alface orgânica influenciado pelo sombreamento, época de plantio e preparo do solo no Acre. Pesquisa Agropecuária Brasileira, v.50, p.468-474, 2015. DOI: 10.1590/ S0100-204X2015000600005.

STAMPS, R.H. Use of colored shade netting in horticulture. Hortscience, v.44, p.239-241, 2009.

TRANI, P.E.; PURQUERIO, L.F.V.; FIGUEIREDO, G.J.B.; TIVELLI, S.W.; BLAT, S.F. Calagem e adubação da alface, almeirão, agrião d'água, chicória, coentro, espinafre e rúcula. Campinas: IAC, 2014. 16p. (IAC. Informações tecnológicas, 97).

Recebido em 24 de abril de 2015 e aprovado em 24 de agosto de 2015 